stimmungen von allergenspezifischen IgE-Konzentrationen im Serum durchgeführt werden. Die Sensitivität scheint dabei etwas geringer als bei dem CAP-System. Die Ergebnisse müssen unter Berücksichtigung der Anamnese und der Hauttestungen interpretiert werden.

\section{Sulfite: ungewöhnliche Kontaktallergene in Haarfärbemitteln?}

\section{P. Spornraft-Ragaller, R. Aschoff, G. Richter}

Klinik und Poliklinik für Dermatologie, Universitätsklinikum Carl Gustav Carus an der Technischen Universität Dresden

Kasuistik: Es wird über eine 29-jährige Patientin berichtet, die sich nach Selbstanwendung eines dunklen Haarfärbemittels eines renommierten deutschen Herstellers mit einer akuten Kontaktdermatitis vorstellte.

Klinischer Befund: Ausgeprägte, nässende Dermatitis im Bereich des Capillitiums, der Ohren und besonders der Augenlider, z. T. Streureaktionen.

Allergietestung: positive Epikutantestreaktionen auf p-Phenylendiamin $(++)$, p-Toluylen-diamin $(+)$, Diaminodiphenylmethan und, wegen der Beteiligung der Augenlider mit getestet, Na-Metabisulfit (1\%) aus dem Augenexterna-Block (bis +++ , Crescendoreaktion). ROAT mit fertiger Färbezubereitung: Ekzemreaktion.

Diskussion: Da die Patientin vor längerer Zeit auch Augentropfen angewendet hatte, wurden diese als Originalpräparat (Indocolir ${ }^{\circledR}$, sulfitfrei) mit getestet, ohne Reaktion. Aufgrund der ausgeprägten Reaktion auf Na-Metabisulfit im Epikutantest nehmen wir an, dass das in dem Haarfärbemittel auch enthaltene Natriumsulfit eines der relevanten Kontaktallergene bei dieser Patientin darstellen könnte. 66 bisher von uns mit Na-Metabisulfit getestete Personen zeigten bis auf die beschriebene Patientin keine Reaktion. Kürzlich wurden einzelne kasuistische Mitteilungen über Kontaktsensibilisierungen gegen Sulfite (Na-Metabisulfit, Na-Sulfit) in Lokaltherapeutika (Steroide, Antimykotika) und im Bäcker-/Konditoreigewerbe berichtet. In der Literatur zu Kontaktallergien gegen Friseurstoffe finden sich jedoch bis auf bestimmte sulfithaltige Dauerwellprodukte kaum Hinweise auf eine mögliche Relevanz dieser Substanzen. Da Sulfite als Antioxidanzien auch in Haarfärbemitteln weit verbreitet sind, sollten sie als mögliche Ursache von Kontaktallergien bei der Testung von Friseurstoffen berücksichtigt werden.

\section{Airborne Kontaktdermatitis bei einem Orthopädiemechaniker}

\section{K. Forschner, T. Zuberbier, M. Worm}

Klinik für Dermatologie Bereich Allergologie, Charité, HumboldtUniversität zu Berlin

Wir berichten über einen 32-Jährigen, der zunehmend, betont im Gesicht, am Hals und oberen Rücken unter juckenden Hauterscheinungen leidet, die sich in arbeitsfreien Zeiten zurückbilden. Als Orthopädiemechaniker besteht eine Bela- stung durch Stäube (Bearbeiten/Schleifen von Gipsmaterial) und Dämpfe (Erhitzen von Härterpaste und Leichtspachtel) am Arbeitsplatz. Die allergologische Anamnese ergab eine intermittierende allergische Rhinitis, der Erlanger-AtopieScore lag bei 3 Punkten. Das Gesamt-IgE im Serum war normal, spezifische IgE-AK waren nur gegenüber Birkenpollen (CAP-II) nachweisbar. Der Prick-Test war positiv bei Beifußund Birkenpollen. Ein auswärtiger Epikutantest (DKG 1, 18) war negativ. Die ergänzende Epikutantestung im Hinblick auf berufsrelevante Allergene (DKG 28, DKG 5 und mitgebrachte Stoffe vom Arbeitsplatz) ergab eine Sensibilisierung gegenüber einem häufig verwendeten Produkt, einer Härterpaste, und dem Produktgemisch aus der Härterpaste und einem Leichtspachtel. Weitere Epikutantestungen mit den Einzelsubstanzen (Härterpaste $10 \%$ mit Benzoylperoxid [BPO] und Härterpaste ohne BPO) ergaben Sensiblisierungen gegenüber Härterpaste mit $\mathrm{BPO}$ (5\%), keine Reaktion gegenüber Härterpaste ohne BPO. Ein folgender Epikutantest mit $0,5 \%, 1 \%, 2,5 \%$ und 5\% BPO in Vaseline war positiv mit eindeutigen allergischen Reaktionen bei allen Konzentrationen. Aufgrund der nachgewiesenen Sensibilisierung wurde, nach Begehung durch den technischen Aufsichtsdienst, ein benzoylperoxidfreies Produkt am Arbeitsplatz verwendet.

BPO ist ein häufiges Irritans mit Sensibilisierungsraten zwischen $1 \%$ und 4,1\%. Wir konnten eine Typ-IV-Sensibilisierung gegenüber BPO als Ursache einer „Airborne Kontaktdermatitis" nachweisen. Unter den eingeleiteten Therapiemaßnahmen sind die Hauterscheinungen im Verlauf vollständig abgeheilt.

\section{Hyposensibilisierung bei Mehlstauballergie B. Hauswald, S. Heilmann, K.-B. Hüttenbrink}

HNO-Universitätsklinik Dresden

Die als Bäckerasthma bezeichnete Sensibilisierung der unteren Atemwege ist bekannt und wird als Diagnose in der ICD10 geführt (J45.0). Die Sensibilisierung der oberen Atemwege geht mit den typischen Symptomen einer allergischen Rhinitis und Konjunktivitis einher, die 5-10 min nach Kontakt mit Mehlstaub auftreten.

In unserer allergologischen Sprechstunde wurde bei insgesamt 38 Patienten eine Mehlstauballergie mittels Anamnese, RAST, Scratch-Test, Prick-in-Prick-Test, Prick-Test, nasalem Applikator-Test (NAPT) und nasalem Provokationstest (NPT) diagnostiziert. Bei 29 Patienten wurde eine einwöchige stationäre Schnellhyposensibilisierung gegen Roggen- und Weizenmehl durchgeführt, gefolgt von einer Erhaltungstherapie über 3-5 Jahre. In unsere Nachuntersuchungen konnten 23 Patienten einbezogen werden.

Die Latenzzeit zwischen Beginn der Berufstätigkeit und Entwicklung einer manifesten Allergie schwankt zwischen 1 und 16 Jahren, im Durchschnitt beträgt die Zeit bis zur Sensibilisierung 6,5 Jahre. Etwa 70\% der behandelten Patienten leiden an einer Zweitallergie. Nach erfolgter Hyposensibilisierung kommt es zu einer deutlichen Reduktion der Beschwerde-Scores. Die berufliche Belastbarkeit ist erhöht und die Le- 